\title{
Effects of hole stress concentration and its mitigation on the tensile strength of sheet moulding compound (SMC-R50) composites
}

\author{
P. K. MALLICK \\ (University of Michigan-Dearborn, USA) \\ The hole stress concentration effects on the tensile strength of \\ SMC-R50 sheet moulding compound composites were studied with \\ consideration being given to both centric and eccentric hole locations. \\ It is shown that the tensile strength of the R50 material is improved by \\ applying a transverse normal pressure around the hole boundary. $A$ \\ few preliminary experiments indicate that the fatigue life of the R50 \\ material can also be improved by a similar technique of applying a \\ transverse normal pressure around an open hole.
}

Key words: composite materials; sheet moulding compounds; mechanical testing; tensile strength; hole stress concentration; fatigue testing

Design of many structural members requires the incorporation of open holes for uses such as connections and access. Holes cause stress concentration in areas adjacent to the hole boundary and reduce the tensile load carrying capacity of the member. In general, the effects of hole stress concentration are measured in terms of the notched tensile stength of flat specimens containing a central hole. Notched tensile strength of two random fibre sheet moulding compound (SMC) composites have been reported earlier. $\mathrm{Hoa}^{1}$ presented data on SMC-R30 (containing 30 (weight) \% of E-glass fibres), while Shirrell and Onachuk ${ }^{2}$ studied the influence of mould coverage on the notched tensile strength of SMC-R25 (containing 25 (weight) \% of E-glass fibres). This paper presents the notched tensile strength data of another SMC material, namely SMC-R50 (containing 50 (weight) $\%$ of E-glass fibres). The effects of both centric and eccentric holes were investigated. The latter condition represents many practical situations where the hole in a structure may be located off-centre relative to the direction of loading. Finally, this paper addresses a simple method of mitigating the hole stress concentration in a member by applying a transverse normal pressure around the hole boundary.

\section{EXPERIMENTAL}

The material investigated in this study was an R50 sheet moulding compound (SMC) composite containing 50\% by weight of $25 \mathrm{~mm}$ long chopped E-glass strands in a vinyl ester resin. The fibres were randomly oriented in the plane of the sMc. Other major ingredients were calcium carbonate (used as a filler), magnesium oxide (used as a thickener) and a thermoplastic additive (used for controlling shrinkage). Sheets of R50 material were stacked and compression moulded into flat plaques with a $2.7 \mathrm{~mm}$ nominal thickness. Resin burn-off tests of samples taken at various locations on the plaques showed a uniform fibre distribution in the plaques.

Rectangular specimens, $100 \mathrm{~mm}$ long by $25 \mathrm{~mm}$ wide, were tested in static tension in a Universal testing machine. Centred as well as off-centred circular holes with diameters ranging from $3.3 \mathrm{~mm}$ to $12.7 \mathrm{~mm}$ were drilled at the mid-lengths of these specimens (Fig. 1). The distance of the centre of the off-centred holes from the specimen centre-line was varied. At least five specimens were tested for each test condition.

Experiments investigating the effects of transverse normal pressure were performed on the specimens with

0010-4361/88/070283-05 \$3.00@1988 Butterworth \& Co (Publishers) Ltd 


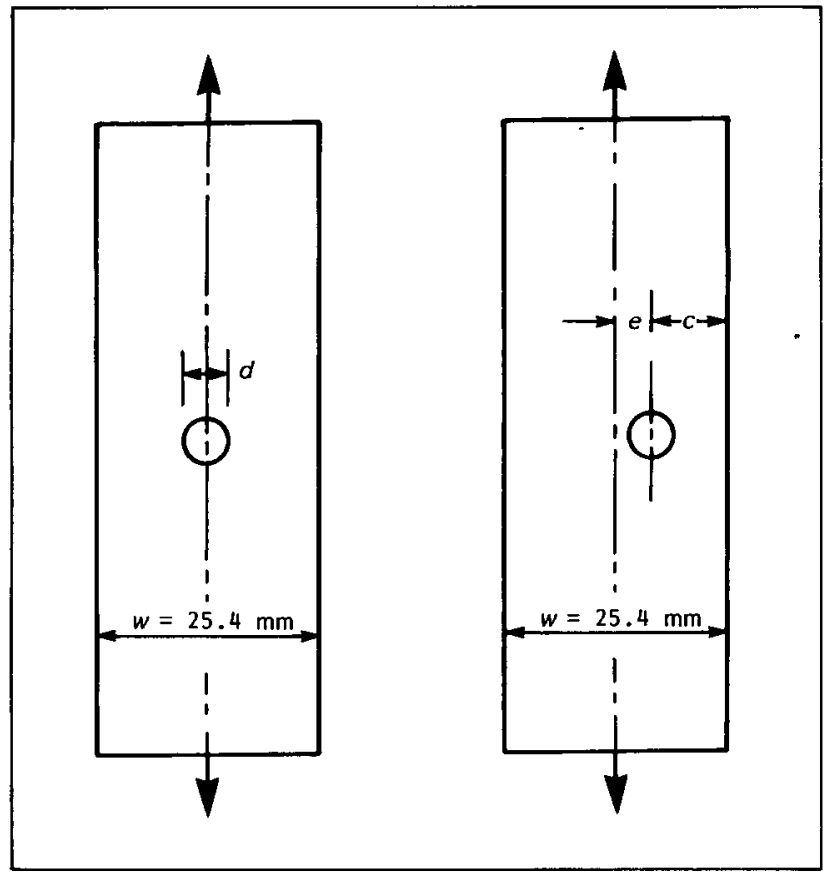

Fig. 1 Specimen configuration with (/eft) centred hole, and (right) off-centred hole centric holes. Transverse normal pressure around the hole was generated by clamping flat washers on both sides of the specimen (Fig. 2) and tightening the nuts to various torque levels. Hard steel washers with rounded edges were used to reduce the damage at the washer boundary. Static tension tests and a few tension-tension fatigue tests were performed with these 'clamped' specimens. Other than the transverse normal pressure, there was no load applied at the clamped hole.

\section{RESULTS}

\section{Static tests}

1. Centric holes: Notched tensile strengths were calculated on the bases of both gross cross-sectional area and net cross-sectional area. The ratio of average notched tensile strength to average unnotched tensile strength is shown in Fig. 3 as a function of the $(d / w)$ ratio $(d=$ diameter of the hole, $w=$ width of specimen). Since the net-area notched tensile strength does not drop appreciably from the unnotched tensile strength even at $(d / w)=0.5$, the particular R50 material tested can be considered relatively notchinsensitive. Similar observations were made by Shirrell and Onachuk ${ }^{2}$ for an R25 SMC composite containing 25 (weight) \% of randomly oriented E-glass fibres in an isophthalic polyester resin. Low hole notch-sensitivity in these materials was attributed to the fact that all compression-moulded SMC materials contain a large number of naturally-occurring flaws, such as voids and fibre ends. As a result, micro-cracks form throughout the specimen long before the actual failure. Microcracks formed at the hole boundary may have the beneficial effect of reducing the stress concentration at the hole edge (similar to the localized yielding in metals) and, thus, reducing the notch sensitivity of the material.

The gross-area notched tensile strength data were fitted to the Whitney-Nuismer Point Stress model ${ }^{3}$.

According to this model, failure in an infinitely wide laminated plate containing a centre hole (Fig. 4) occurs at a stress level $\sigma_{n}$ which is given by:

$$
\sigma_{\mathrm{n}}=\left[\frac{2}{2+\lambda^{2}+3 \lambda^{4}-\left(K_{\mathrm{T}}-3\right)\left(5 \lambda^{6}-7 \lambda^{8}\right)}\right] \sigma_{0}
$$

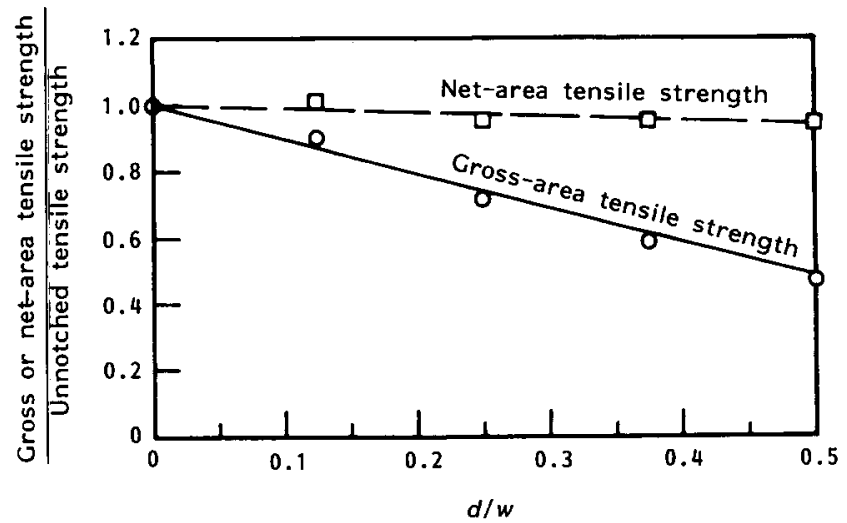

Fig. 3 Tensile strength variation in specimens with centred holes

Fig. 2 Specimen configuration with a centred clamped hole 


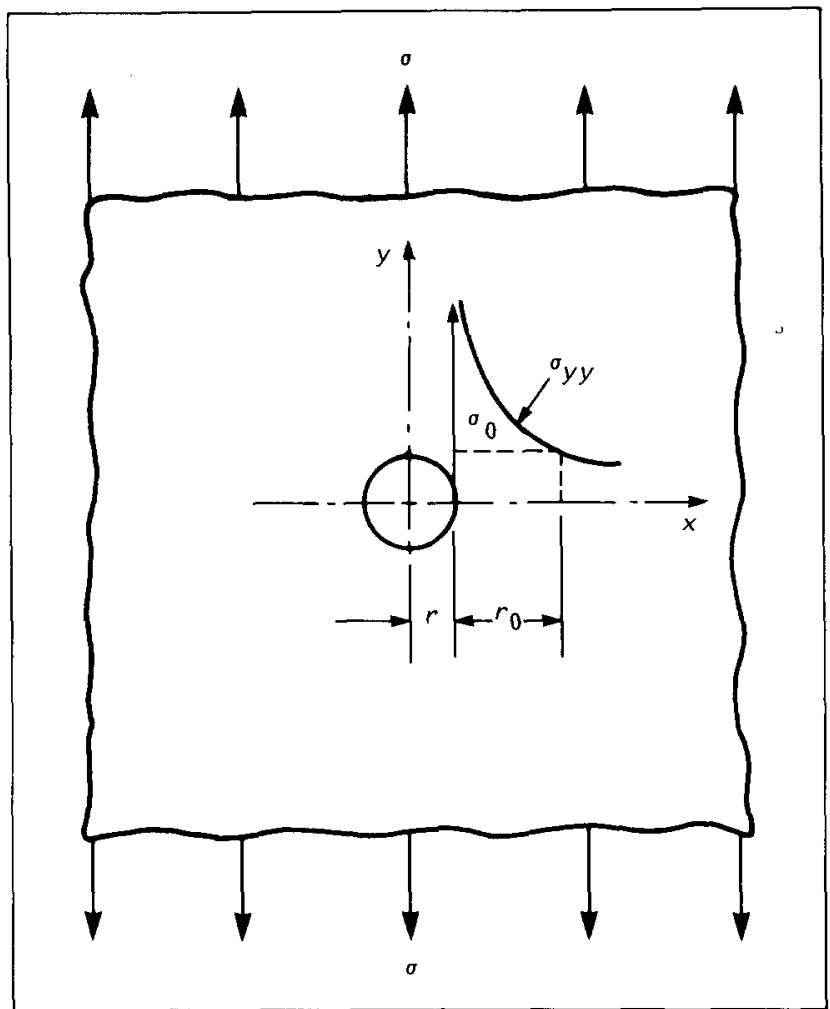

Fig. 4 An infinitely wide plate with a circular hole of radius $r$ subjected to uniaxial tensile load

where, $\sigma_{0}=$ unnotched tensile strength of the laminate material, $K_{\mathrm{T}}=$ theoretical stress concentration factor, $\lambda=r /\left(r+r_{0}\right), r=$ hole radius, and $r_{0}=$ a characteristic distance from the hole edge (obtained by fitting Equation (1) to experimental data). The characteristic distance $r_{0}$ represented the distance from the hole edge at which the tensile stress due to the applied load is equal to the unnotched tensile strength of the laminate material.

Since, for all practical purposes, the R50 composite can be considered an isotropic material, $K_{\mathrm{T}} \approx 3$ and, therefore, Equation (1) transforms into:

$$
\sigma_{\mathrm{n}}=\left[\frac{2}{2+\lambda^{2}+3 \lambda^{4}}\right] \sigma_{0}
$$

The specimens used in this work had relatively narrow width compared with the hole size. Therefore, a finite width correction factor was applied to Equation (2) for calculating the theoretical gross-area notched tensile strength. The finite width correction factor, taken from Reference 4, is given by:

$$
C_{\mathrm{w}}=1-0.05\left[\frac{d}{w}\right]+1.5\left[\frac{d}{w}\right]^{2}
$$

(where, $d=2 r$ ).

Combining Equations (2) and (3), the theoretical gross-area notched tensile strength $\sigma_{\text {gn }}$ can be written as:

$$
\sigma_{\mathrm{gn}}=\frac{\sigma_{\mathrm{n}}}{C_{\mathrm{w}}}=\left[\frac{2}{2+\lambda^{2}+3 \lambda^{4}}\right] \frac{\sigma_{0}}{C_{\mathrm{w}}}
$$

The value of $r_{0}$ was determined using Equation (4) and the average gross-area notched tensile strength of

Table 1. Gross-area notched tensile strength of SMC-R50 composites

Hole diameter $(\mathrm{mm})$

$\begin{array}{lrr}0 & 146.2 & - \\ 3.17 & 131.0 & 131.6 \\ 6.35 & 103.5 & 107.2 \\ 9.52 & 86.5 & 85.4 \\ 12.7 & 68.7 & 68.1\end{array}$

* Whitney-Nuismer Point Stress model with $r_{0}=2.8 \mathrm{~mm}$ and corrected for finite width

specimens containing a $3.17 \mathrm{~mm}$ diameter hole. This value was $2.8 \mathrm{~mm}$. Using this value of $r_{0}$, theoretical strength values were calculated for specimens containing $6.35,9.52$ and $12.7 \mathrm{~mm}$ diameter holes. As Table 1 shows, these theoretical strength values compare very closely with the experimentally observed values. Thus, it is concluded that the Whitney-Nuismer Point Stress model can be used to predict the notch sensitivity of SMC-R50 composites. Similar observations were also made by Shirrell and Onachuk ${ }^{2}$ for the SMC-R25 material.

2. Off-centred holes: Both gross-area and net-area notched tensile strengths for specimens containing off-centred holes are shown in Fig. 5. The net-area

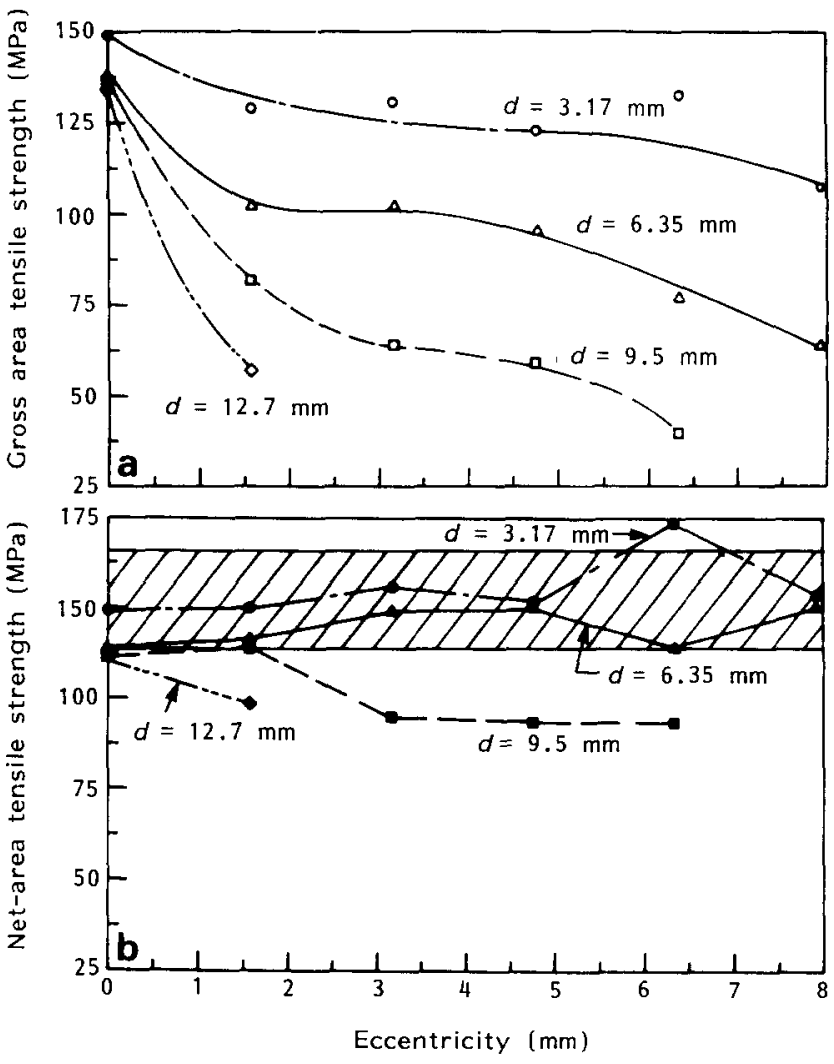

Fig. 5 Tensile strength variation in specimens with off-centred holes: (a) gross-area notched tensile strength; and (b) net-area notched tensile strength. (The cross-hatched area indicates the range of unnotched strengths observed for SMC-R50 laminates) 
notched tensile strengths were calculated using the following equation: ${ }^{5}$

$$
\begin{aligned}
& \sigma_{\mathrm{n}}=\left(\frac{P}{w t}\right) \\
& \times \frac{\sqrt{1-\left(\frac{d}{2 c}\right)^{2}}}{1-\left(\frac{d}{2 c}\right)} \cdot \frac{\left(1-\frac{c}{w}\right)}{1-\frac{c}{w}\left[2-\sqrt{1-\left(\frac{d}{2 c}\right)^{2}}\right]}
\end{aligned}
$$

where $P=$ load at failure, $w=$ specimen width, $t=$ specimen thickness and $c=$ distance from the hole centre to the nearest specimen edge (see Fig. 1). Equation (5) takes into account the effects of bending moment as well as the normal forces which result due to the eccentricity of the hole.

Fig. 5 shows that the effect of off-centred holes on the tensile strength of R50 composites depends on the hole eccentricity as well as the hole diameter. For small hole eccentricities, there was very little reduction in tensile strength; however, as the hole edge nears the specimen edge, there can be a severe reduction in the gross-area notched tensile strength. For $d=3.17$ and $6.35 \mathrm{~mm}$, the net-area notched tensile strength is within the range of unnotched tensile strength values observed for this material. However, with larger hole diameter, the net-area notched tensile strength is reduced. For a few holes located very close to the specimen edge, failure took place in two steps. First, the narrow ligament between the hole edge and the specimen edge ruptured, then the load continued to rise until failure occurred across the remainder of the specimen width.

3. Holes with transverse normal pressure: The transverse normal pressure exerted by the washers on the specimen can be estimated from the clamp-up torque using the following equation: ${ }^{6}$
Table 2. Effect of bolt clamp-up torque on the tensile strength

\begin{tabular}{|c|c|c|c|c|c|c|c|}
\hline \multirow[t]{2}{*}{$\begin{array}{l}\text { Hole } \\
\phi(\mathrm{mm})\end{array}$} & \multirow[t]{2}{*}{$\begin{array}{l}\text { Ratio of } \\
\text { hole } \phi \\
\text { to } \\
\text { washer } \\
\text { outer } \phi\end{array}$} & \multirow[t]{2}{*}{$\begin{array}{l}\text { Torque } \\
\text { (N m) }\end{array}$} & \multirow[t]{2}{*}{$\begin{array}{l}\text { Estimated } \\
\text { transverse } \\
\text { normal } \\
\text { pressure } \\
\text { (MPa) }\end{array}$} & \multicolumn{2}{|c|}{$\begin{array}{l}\text { Net-area } \\
\text { tensile } \\
\text { stress at } \\
\text { failure } \\
\text { (MPa) }\end{array}$} & \multicolumn{2}{|c|}{$\begin{array}{l}\text { Gross-area } \\
\text { tensile } \\
\text { stress at } \\
\text { failure } \\
\text { (MPa) }\end{array}$} \\
\hline & & & & Mean & $\begin{array}{l}\text { St } \\
\text { dev }^{*}\end{array}$ & Mean & $\begin{array}{l}\text { St } \\
\text { dev* }^{*}\end{array}$ \\
\hline 9.52 & 0.429 & $\begin{array}{l}0 \\
9 \\
18 \\
27 \\
43.4\end{array}$ & $\begin{array}{l}0 \\
17.6 \\
35.2 \\
53.0 \\
84\end{array}$ & $\begin{array}{l}138.6 \\
171.8 \\
185.6 \\
214.5 \\
240.9\end{array}$ & $\begin{array}{c}5.9 \\
14.7 \\
10.69 \\
8.55 \\
20.7\end{array}$ & $\begin{array}{r}86.5 \\
107.8 \\
127.9 \\
134.7 \\
150.2\end{array}$ & $\begin{array}{c}3.6 \\
9.2 \\
0.94 \\
5.4 \\
12.8\end{array}$ \\
\hline 6.35 & 0.422 & $\begin{array}{r}0 \\
9 \\
18\end{array}$ & $\begin{array}{r}0 \\
65 \\
130\end{array}$ & $\begin{array}{l}138.2 \\
176.1 \\
202.8\end{array}$ & $\begin{array}{r}9.5 \\
7.3 \\
16.9\end{array}$ & $\begin{array}{l}103.5 \\
131.9 \\
152\end{array}$ & $\begin{array}{r}7.1 \\
5.6 \\
12.3\end{array}$ \\
\hline 12.5 & 0.5 & $\begin{array}{c}0 \\
9 \\
18 \\
27 \\
43.4\end{array}$ & $\begin{array}{c}0 \\
9.8 \\
19.5 \\
29.3 \\
46.8\end{array}$ & $\begin{array}{l}137.1 \\
165.7 \\
199.6 \\
247 \\
256.5\end{array}$ & $\begin{array}{l}12.5 \\
14.3 \\
10.7 \\
23.45 \\
18.5\end{array}$ & \begin{tabular}{r|}
68.7 \\
83.6 \\
98.7 \\
124.3 \\
129.2
\end{tabular} & $\begin{array}{c}6.55 \\
6.9 \\
4.9 \\
11.2 \\
9.45\end{array}$ \\
\hline
\end{tabular}
of SMC-R50 composites with centric holes

* Stendard deviation

$$
p_{\mathrm{n}}=\frac{T}{0.2 d_{\mathrm{b}} A_{\mathrm{w}}}
$$

where, $p_{\mathrm{n}}=$ transverse normal pressure, $T=$ clamp-up torque, $d_{\mathrm{b}}=$ bolt diameter, and $A_{\mathrm{w}}=$ washer surface area.

Thus, increasing the clamp-up torque creates higher transverse normal pressure around the hole in the specimen.

The effect of increasing clamp-up torque on the notched tensile strength of R50 specimens is shown in Table 2. It is to be noted that the gross-area notched tensile strength observed for clamped specimens increased with increasing clamp-up torque. At relatively high torque values, the gross-area notched

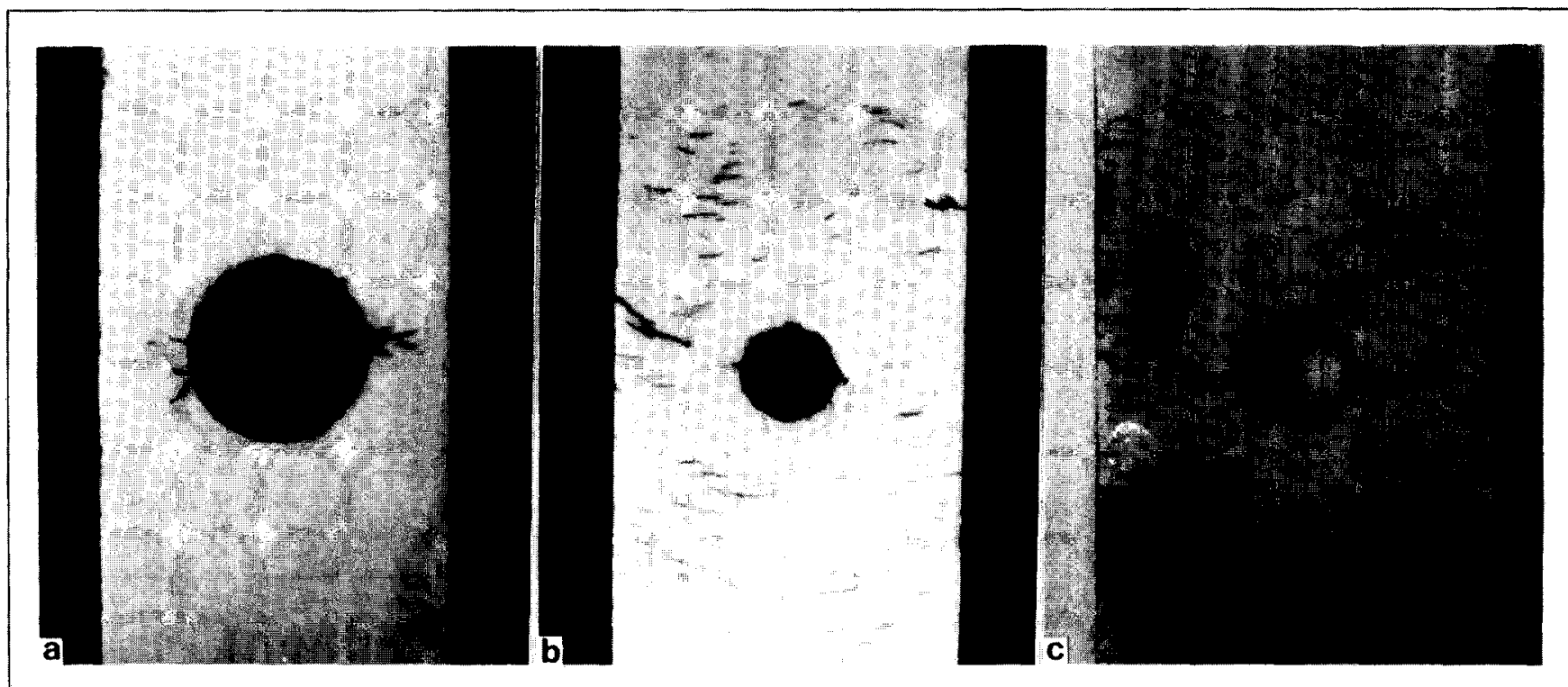

Fig. 6 Crack development in notched specimens: (a) unclamped; (b) clamped hole with major crack developing outside the washer edge; and (c) clamped hole with major crack developing in the clamped area 
tensile strength of clamped specimens was within the scatterband of the unnotched tensile strength, while the gross-area notched tensile strength of unclamped specimens (Fig. 3) decreased with increasing hole diameter. It is interesting to note that the net-area notched tensile strength of clamped specimens continued to increase with increasing clamp-up torque.

The development of major cracks in both unclamped and clamped specimens was followed by loading several specimens to a sequence of increasing tensile stresses. The unloaded specimens were painted with a red marker which revealed the crack pattern on the specimen surface. In unclamped specimens, the major crack originated from the hole edge and proceeded toward the specimen edges (Fig. 6(a)), while in clamped specimens, the area under the washer remained virtually crack-free (Fig. 6(b)). The cluster of cracks formed outside the clamped area seemed to have stopped at the washer boundary. For these specimens, the major crack formed either at the specimen edge and proceeded inward, or, in some specimens, cracks originated under the washer caused the ultimate failure (Fig. 6(c)).

\section{Fatigue tests}

A few load-controlled fatigue tests were performed in tension-tension mode on both unclamped and clamped specimens containing 6.35 or $9.52 \mathrm{~mm}$ diameter centric holes. The maximum fatigue stress was $80 \%$ of the average gross-area notched tensile strength for each hole diameter. A nominal non-zero minimum tensile stress was maintained on each specimen. The purpose of these fatigue tests was to explore whether the transverse normal pressure induced by the clamp-up torque had any beneficial effect on the fatigue performance of the R50 material. For comparison, the tension-tension fatigue strength of unnotched SMCR50 material is reported as only $39 \%$ of its unnotched tensile strength. ${ }^{7}$

Fatigue test data are summarized in Table 3 . It is to be noted that the maximum fatigue stress levels for clamped specimens were greater than those used for unclamped specimens, yet the clamped specimens showed a tendency to endure higher cycles to failure. For unclamped specimens, major fatigue cracks originated at the hole edge and the final rupture took place when these cracks moved outward toward the specimen edges. Two of the clamped specimens failed by rupture at the hole. However, in unfailed clamped specimens, there was ample evidence that the fatigue cracks originated outside the clamped area and were stopped at the washer boundary.

\section{CONCLUSIONS}

SMC-R50 composites exhibit relatively low notchsensitivity. Their notched tensile strength can be predicted using the Whitney-Nuismer Point Stress model and $r_{0}=2.8 \mathrm{~mm}$.

Large hole eccentricity can cause a large reduction in the notched tensile strength of SMC-R50 composites.
Table 3. Exploratory fatigue test data

\begin{tabular}{|c|c|c|c|}
\hline $\begin{array}{l}\text { Hole } \\
\text { diameter } \\
(\mathrm{mm})\end{array}$ & Condition & $\begin{array}{l}\text { Max stress } \\
\text { (MPa) }\end{array}$ & $\begin{array}{l}\text { Cycles } \\
\text { endured }\end{array}$ \\
\hline 6.35 & Unclamped & 84 & $\begin{array}{r}163 \\
181 \\
72 \\
403 \\
346\end{array}$ \\
\hline 6.35 & $\begin{array}{c}\text { Clamped } \\
9 \mathrm{~N}-\mathrm{m} \\
9 \mathrm{~N}-\mathrm{m} \\
18 \mathrm{~N}-\mathrm{m}\end{array}$ & $\begin{array}{r}85.2 \\
100.9 \\
116.6\end{array}$ & $\begin{array}{c}>1850^{*} \\
>1170^{*} \\
812\end{array}$ \\
\hline 9.52 & Unclamped & 67.4 & $\begin{array}{r}104 \\
315 \\
1101\end{array}$ \\
\hline 9.52 & $\begin{array}{c}\text { Clamped } \\
9 N-m \\
9 N-m \\
9 N-m\end{array}$ & $\begin{array}{l}67.7 \\
83.4 \\
83.4\end{array}$ & $\begin{array}{c}>375^{*} \\
249 \\
>375^{*}\end{array}$ \\
\hline
\end{tabular}

* Test discontinued to examine the specimen

Transverse normal pressure created by bolt clamping at open holes can be used to mitigate the hole stress concentration in SMC-R50 composites. This method may be particularly beneficial in stopping fatigue cracks at the open holes.

\section{ACKNOWLEDGEMENT}

The author wishes to thank the University of MichiganDearborn for supporting this project with a campus grant.

\section{REFERENCES}

1 Hoa, S. V. 'Effect of hole size on the stress concentration of sheet molding compounds' Proc 39th Annual Tech Conf (SPE, 1981)

2 Shirrell, C. D. and Onachuk, M. G. 'Influence of mold coverage upon the notch strength of R25 sheet molding compounds,' Composite Materials: Fatigue and Fracture, ASTM STP 907 (ASTM 1986)

3 Whitney, J. M. and Nuismer, R. J. 'Stress Fracture Criteria for Laminated Composites containing Stress Concentrations' $J$. Comp Mater 8 (1974) p 253

4 Peterson, R. E. Stress Concentration Factors (John Wiley \& Sons, 1974)

5 Roark, R. J. and Young, W. C. Formulas for Stress and Strain, Fifth Edition (McGraw-Hill Book Co, 1975)

6 Shigley, J. E. and Mitchell, L. D. Mechanical Engineering Design, Fourth Edition (McGraw-Hill Book Co, 1983)

7 Denton, D. 'Mechanical properties characterization of an SMC-R50 composite' Paper No 790671 (Society of Automotive Engineers, Inc, 1979)

\section{AUTHOR}

The author is Associate Professor at the Department of Mechanical Engineering, University of Michigan-Dearborn, Dearborn, MI 48128, USA. 